\title{
AC 2008-216: SEA-BASED AVIATION TO BRIDGE THE GAP BETWEEN AEROSPACE AND NAVAL ENGINEERING STUDENTS
}

\section{Leigh McCue, Virginia Polytechnic Institute and State University}

Leigh McCue is an Assistant Professor in Virginia Tech's Department of Aerospace and Ocean Engineering and an affiliate to the VT Department of Engineering Education. Her research interests are in nonlinear and chaotic vessel dynamics including capsize, parametric rolling, and sea-based aviation operations largely involving analytical and numerical approaches. Dr. McCue received her BSE degree in Mechanical and Aerospace Engineering in 2000 from Princeton University. She earned her graduate degrees from the University of Michigan in Aerospace Engineering (MSE 2001) and Naval Architecture and Marine Engineering (MSE 2002, PhD 2004).

\section{Christina Pace, Virginia Polytechnic Institute and State University}

Christina Pace is a 2007 graduate of Virginia Tech's Mathematics program. In the fall of 2008 she will begin graduate studies in Mathematics Education at the University of Georgia. There she hopes to create a curriculum based around special education, educational psychology, and mathematics. Her primary research interests are integrated and differential education. She has two dogs, Gracie and Marzipan. 


\section{Sea-based aviation to bridge the gap between aerospace and naval engineering students}

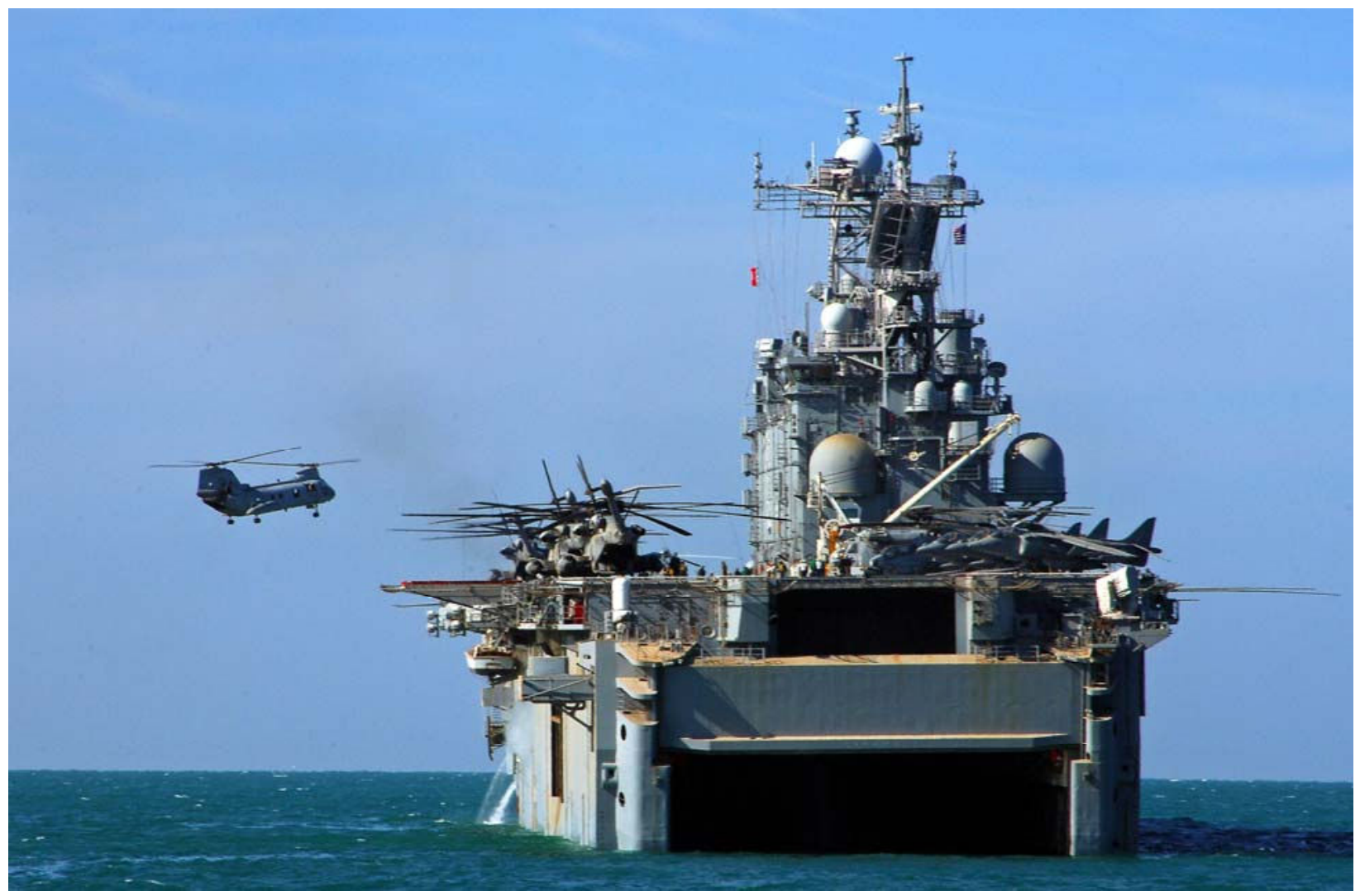

U.S. Navy photo by MCSN David A. Brandenburg

\section{Abstract}

This case study focuses upon encouraging discussion and awareness of aerospace and naval engineering opportunities in a classroom comprised of both majors through a two-part (individual and group) project on sea-based aviation. In this paper, the result of the students interactive thought process is summarized with input as to how to make similar exercises more effective in future course offerings. Additionally, student feedback as to the use of this assignment for emphasizing to them the importance of a multi-disciplinary (multi-vehicle) systems perspective rather than a unit perspective is presented.

\section{Introduction}

The Virginia Tech course AOE4334 "Ship Dynamics" is a required part of the core "Ocean Engineering" curriculum. Because of the uniqueness of the department as an Aerospace and Ocean Engineering combination and the intertwining of the Aerospace and Ocean Engineering majors within the department, a number of students choose to double major. In the 2007 AOE4334 course, of 20 students, 13 were pure ocean engineering majors, 2 were dual majors with ocean engineering listed as their primary major, and 5 were dual majors with aerospace 
engineering as their primary. To help encourage recognition of aerospace engineering constraints within the naval engineering field and vice versa, a two-part project on sea-based aviation was assigned. The first half of the project, assigned to be completed by the midterm, tasked students to consider the task of landing a helicopter on the deck of a ship from the perspective of the naval engineer (the ship's needs) or the aerospace engineer (the helicopter's needs). Students were allowed to choose the ship or helicopter perspective, regardless of major. For the second half of the project, the self-defined aerospace and naval engineers were paired to re-evaluate the problem and present both difficulties associated with ship-helicopter interactions and potential solutions/compromises. The project was deliberately open-ended to allow students maximum freedom, but they were encouraged to view the assignment as a challenge to formulate design constraints and/or potential ship owner requirements.

\section{Background}

\section{Definition}

Newell defines inter-disciplinary studies as that which "draws insights from relevant disciplines and integrates those insights into a more comprehensive understading" . According to Newell, for a topic to be considered for inter-disciplinary studies, it must be both multi-faceted and coherent ${ }^{1}$. By requiring it to be multi-faceted, different disciplines are needed to address the topic at hand. Without this qualification it could be justly handled by a single discipline. By requiring it to be coherent, the different disciplines are forced to work together to address the topic. Newell refers to these multi-faceted, coherent concepts, as complex ideas and deems them the only ideas worthy of consideration for inter-disciplinary studies ${ }^{1}$.

Why use an inter-disciplinary approach to education?

Klein ${ }^{2}$ suggests that the reasons why an inter-disciplinary approach is used can be just as important as the approach itself. She discourages the use of an interdisciplinary approach for reasons such "as a social need, a politically correct concept, or a justification for organizational and management strategies and pedagogical practices that do not respect educational outcomes, disciplinary structures, or learning processes." 2 It is important to remember that education is the foundation of the study. If you lose sight of the goal, which is ultimately to learn, you will never achieve it. Klein adds that "a fuller understanding of historical context, definition, and patterns of practice is required" ${ }^{2}$ before being able to develop a curriculum or even a project based in more than one discipline.

\section{Benefits of an Inter-Disciplinary Education}

Several factors inherent to an interdisciplinary classroom model, such as group work, heightened rigor challenging students, and making connections between disciplines, support educational growth. All of these factors contribute to the effectiveness of interdisciplinary education. Additionally, a group dynamic is crucial. Davis notes that not only do students learn more when they are working in a group, but they get more satisfaction out of the work that they $\mathrm{do}^{3}$. Often group projects are designed to be larger and more intricate than projects for one person. Because of this, students must work together to divide up the work and get the entire assignment done. In doing this, students are forced to communicate with each other, learn from each other, and unite their own expertise with that of the group. Students working in groups understand that their success depends on the success of the entire group and knowing this can be a motivator ${ }^{3}$. 
Students enjoy rising to a challenging task; one could certainly argue that it is much better for students to be engaged and learning challenging material than bored and working on easier assignments. One of the main benefits of an inter-disciplinary project is students will have access to subjects they are less familiar with. This poses a challenge and adds to student learning. Students from different disciplines teach each other about their specialty thus increasing the collective breadth of knowledge.

One of the main benefits of an interdisciplinary education is that students are able to see how subjects fit together. In Humphreys et al, Interdisciplinary Methods: A Thematic Approach, it is stated that children "learn what we teach. If we teach connectedness and integration, they learn that. If we teach separation and discontinuity, that is what they learn"4. By providing students with an integrated curriculum and opportunity for inter-disciplinary studies, students are allowed to build bridges and make connections on their own. When this happens, they are fueling themselves and enabling their own learning reinforcing the notion of life-long learning.

\section{Interdisciplinary Approaches in Action}

Interdisciplinary approaches have been used in a wide variety of educational settings. Team competitions, such as Solar Challenge, Concrete Canoe, Human Powered Submarine, etc..., and even degree/certificate programs, such as Virginia Tech's Green Engineering minor all foster interdisciplinary teams. Courses and programs (even new fields) have been developed around the context of interdisciplinary education. For example, a semester course on Mechatronics at Clemson University ${ }^{6}$ is made up of both mechanical engineering and electrical \& computer engineering undergraduate and graduate students. Each team is comprised of a graduate student from one of the departments, and an undergraduate student from each department; none of the students would have been required to take a course in the other discipline, yet the students successfully team to complete mini projects and a final project ${ }^{6}$. Inter-disciplinary research and educational methodologies have been applied to a wide variety of topics from mechatronics ${ }^{6}$ to linguistics ${ }^{7}$ to Assyrian culture ${ }^{8}$. In this work, we look at incorporating an interdisciplinary aspect to a pre-existing 'traditional' course in the ocean engineering curriculum. It is also important to note that ABET specifically states that graduates of accredited engineering curriculums must attain "an ability to function on multi-disciplinary teams 9 ."

\section{Student approaches}

In the first half of the semester, students were given the following instruction:

Consider the task of landing a helicopter on the deck of a ship. There are unique issues associated with the aeronautical design (ie the needs of the helicopter to land on the ship) and the mission of the ship (and how it makes use of the helicopter). For this portion of the project begin by deciding if you wish to view the problem as an 'aerospace engineer' or as a 'naval architect'. Define the design problem from your chosen perspective including a detailed list of needs and considerations. This is a research project; you are expected to demonstrate knowledge beyond that contained in wikipedia or presented in the course notes! 
The problem statement was deliberately open-ended. Because this was the first time this project was implemented in AOE4334, the instructor was interested to see how senior-level students, operating relatively freely, would respond to the task. Perhaps due to the joint nature of the department, for the most part, students were surprisingly, and impressively, accommodating to the design considerations required for both aspects of the ship-helicopter launch/recovery problem. Many students explicitly discussed aspects of design more aptly concerns of their counterparts in the field they did not select.

For the second half of the semester, students were given the revised instruction:

Consider the task of landing a helicopter on the deck of a ship. There are unique issues associated with the aeronautical design (ie the needs of the helicopter to land on the ship) and the mission of the ship (and how it makes use of the helicopter). For this portion of the project you are teamed with aerospace engineers representing the needs of the helicopter and naval architects representing the needs of the ship (see assigned teams below). Define the design problem from your group perspective including a detailed list of needs, considerations, and compromises. Discuss all design trade-offs balancing ship space, size, and cost with safe and secure helicopter operations. This is a research project; you are expected to demonstrate knowledge beyond that contained in wikipedia or presented in the course notes. Team work is a must. Your grade on Part B will be determined in part by the grades assigned to you by your teammates!

Teams of four were assigned by the instructor balancing aerospace engineer/naval architect representation and relative student strengths in each group. While students embraced the team nature and seemed highly able to resolve conflicts such as where to put the landing deck, if there should be a hangar, limitations on roll and/or pitch motion, etc..., many more detail aspects (where to put wind anemometers, how to design such to reduce roll and/or pitch motion while still meeting mission requirements) were neglected.

\section{Student feedback}

Student sentiments to the project were mixed with comments [spelling corrected] ranging from "I thought the project was useful. Gave a chance to see the concerns of the aerospace eng when designing a ship" to "Project wasn't very useful." Student comments indicated a need for greater direction in the project. A selected subset of questions deemed fitting in the consideration of the contribution of this project to the course from quantitative course evaluation data are summarized in Table 1 below. The first five questions listed below were evaluated on a 4-point Likert scale (1=poor, $4=$ excellent) while the last three solicited responses on a 3-point scale ( $1=$ less than average, $2=$ average, $3=$ more than average). Unlike 2005 and 2006, the 2007 course offering had a small online section in addition to the in-class section. The online and in-class surveys differ on some questions - those questions which do not appear in the online course evaluation are left blank in the appropriate cells of Table 1. For comparison, data for the 2005 and 2006 course offerings, without the course project, are also included. 


\begin{tabular}{|c|c|c|c|c|}
\hline Question & $\begin{array}{c}2007 \\
\text { Online } \\
\text { Section } \\
(\mathrm{N}=2)\end{array}$ & $\begin{array}{c}2007 \text { In- } \\
\text { Class } \\
\text { Section } \\
(\mathrm{N}=16) \\
\end{array}$ & $\begin{array}{c}2006 \text { In- } \\
\text { Class } \\
\text { Section } \\
(\mathrm{N}=26) \\
\end{array}$ & $\begin{array}{c}2005 \text { In- } \\
\text { Class } \\
\text { Section } \\
(\mathrm{N}=21) \\
\end{array}$ \\
\hline \multicolumn{5}{|c|}{ How I rate the instructor compared with others I have had at Virginia Tech: } \\
\hline $\begin{array}{l}\text { Apparent knowledge of subject } \\
\text { matter }\end{array}$ & $3.5 / 4.0$ & $4.0 / 4.0$ & $3.9 / 4.0$ & $3.9 / 4.0$ \\
\hline $\begin{array}{l}\text { Success in communicating or } \\
\text { explaining subject matter }\end{array}$ & $3.5 / 4.0$ & $3.4 / 4.0$ & $3.3 / 4.0$ & $3.0 / 4.0$ \\
\hline $\begin{array}{l}\text { Degree to which subject matter } \\
\text { was made stimulating or relevant }\end{array}$ & $3.0 / 4.0$ & $3.3 / 4.0$ & $3.4 / 4.0$ & $2.9 / 4.0$ \\
\hline Overall rating of this instructor. & $3.5 / 4.0$ & $3.8 / 4.0$ & $3.7 / 4.0$ & $3.5 / 4.0$ \\
\hline \multicolumn{5}{|c|}{ How I rate or describe this course compared with others I have taken at Virginia Tech: } \\
\hline $\begin{array}{l}\text { Educational value of out-of-class } \\
\text { assignments }\end{array}$ & & $3.4 / 4.0$ & $3.4 / 4.0$ & $3.2 / 4.0$ \\
\hline \multicolumn{5}{|c|}{ I would rate my gains in this course compared with similar courses as follows: } \\
\hline $\begin{array}{l}\text { Knowledge of principles, } \\
\text { theories, techniques, etc. }\end{array}$ & & $2.4 / 3.0$ & $2.1 / 3.0$ & $2.2 / 3.0$ \\
\hline $\begin{array}{l}\text { Logical thinking and problem } \\
\text { solving ability. }\end{array}$ & & $2.3 / 3.0$ & $2.2 / 3.0$ & $2.1 / 3.0$ \\
\hline $\begin{array}{l}\text { Appreciation of the subject } \\
\text { matter and discipline field. }\end{array}$ & & $2.3 / 3.0$ & $2.2 / 3.0$ & $2.2 / 3.0$ \\
\hline
\end{tabular}

\section{Table 1: Fall 2007 Pertinent Course Evaluation Statistics}

Interestingly, there did not appear to be a strong correlation between students giving positive or negative written feedback on the project versus the numerically rated perceived educational value of out-of-class assignments. In fact, the students providing negative feedback on the project gave a higher than class-average response to the question pertaining to educational value of out-of-class assignments, perhaps validating the use of the project in the course. We do note that the in-class section student perceptions of each of these measures appears to have relatively maintained or improved in the 2007 course offering. However, the authors resist drawing too broad a conclusion from comparison with prior years course offerings as the general improvements in student scores are likely due to a number of factors including the recording of the Fall 2007 lectures to serve the online section (which benefited the in-class students as well), the smaller class size in 2007, general increased instructor experience, and year-to-year fluctuations in class 'personality'.

\section{Conclusions and recommendations}

The cross-disciplinary approach to studying ship motions served as a valuable means to engage both aerospace and naval engineering students, as well as to highlight the concept of design tradeoffs graduates will encounter in the working world. The topic was chosen based on the logical combination of the students' fields and the research interest of the instructor ${ }^{10}$. As aftermath of this project, students were encouraged to submit their findings to a poster competition for the upcoming 2008 ASNE Symposium on the Launch and Recovery of Manned 
and Unmanned Vehicles from Surface Platforms. Thus this project served the dual purpose of providing an interdisciplinary educational opportunity and introducing students to research.

In future years, the problem statement will likely be more specific, and require a design drawing of the proposed ship to accommodate a specified helicopter. Students themselves highlighted the need for more project direction, with comments such as "AE/OE project was a good way to incorporate the AE students although I felt the project needed a little more direction as to what exactly was needed." Many of the tradeoffs the students proposed would be unrealistic, in practice, after all, no ship can do everything. A required drawing would cause students to think in greater detail about the mission requirement of the ship and the needs of the helicopter, rather than approaching the problem in a topical, and perhaps unrealistic manner. Furthermore, this may be used as an opportunity to require students to practice using design software to calculate ship specific capabilities. It is a delicate matter, however, to prevent this form of project evolving into a full design course type project rather than a small cross-disciplinary thought exercise.

\section{Acknowledgements}

Leigh McCue thanks Judah Milgram and Lt. Brook Sherman for first getting her excited about the topic of sea-based aviation. Additionally, she wishes to acknowledge travel support from the Virginia Tech Center for the Enhancement of Engineering Diversity and Associate Dean Bevlee Watford. Much of the AOE4334 course is based upon Armin Troesch's University of Michigan NA440 course.

\section{Bibliography}

1. Newell, W.H. "A Theory of Interdisciplinary Studies," Issues of Integrative Studies, No. 19, 2001, pp.1-25.

2. Klein, J. T., "A Platform for a Shared Discourse of Interdisciplinary Education," Journal of Social Science Education, 2006.

3. Davis, B.G.. "Collaborative Learning: Group Work and Study Teams," Tools for Teaching, http://teaching.berkeley.edu/bgd/collaborative.html, 2002.

4. Humphreys, A., Post, T. and Ellis, A., Interdisciplinary Methods: A Thematic Approach, Santa Monica, CA: Goodyear Publishing Company, 1981, as quoted in Lake 5 .

5. Lake, K., "Integrated Curriculum." School Improvement Research Series \#16.

6. Rahn, C.D., Dawson, D.M., and Paul, F.W., "Development of a cross-disciplinary mechatronics course," ASEE/IEEE Frontiers in Education '95, available online at: http://fie.engrng.pitt.edu/fie95/4a1/4a13/4a13.htm, 1995.

7. Niemczura, M. A. and Clayton, J.A.. "The German Toyshop: An Interdisciplinary Project." Die Unterrichtspraxis / Teaching German, Vol. 24, No. 2 (Autumn, 1991), pp. 205-208

8. Arvanitis, T., Davis, T., Livingstone, A., Pinilla-Dutoit, J., and Woolley, S., "The Digital Classification of Ancient Near Eastern Cuneiform Data," available online at: http://www.english.bham.ac.uk/staff/tom/research/cuneiform/tuscany/index.htm, accessed 2008.

9. ABET Engineering Accreditation Commission, 2007-2008 Criteria for accrediting engineering programs, Baltimore, MD, 2007.

10. Sherman, B., McCue, L.S., Bi, P., and Milgram, J., "Assessing the effectiveness of dynamic deck motion limit systems," Conference Paper No. PRADS2007-20290, $10^{\text {th }}$ International Symposium on Practical Design of Ships and Other Floating Structures, Houston, Texas, October, 2007. 